\title{
Antiangiogenic properties of caudatin in vitro and in vivo by suppression of VEGF-VEGFR2-AKT/FAK signal axis
}

\author{
XINZHI WANG ${ }^{1-3^{*}}$, XIAOTING FU ${ }^{3 *}$, SHIJUN ZHAO ${ }^{3}$, XIAOYAN FU ${ }^{3}$, \\ HUIFANG ZHANG ${ }^{3}$, LURONG SHAO ${ }^{3},{\text { GANG } \mathrm{LI}^{1} \text { and CUNDONG FAN }}^{3}$ \\ ${ }^{1}$ Department of Neurosurgery, Qilu Hospital of Shandong University, Jinan, Shandong 250012; ${ }^{2}$ Department of Neurosurgery, \\ The Second People's Hospital of Liaocheng, Liaocheng, Shandong 252601; ${ }^{3}$ Key Lab of Cerebral Microcirculation \\ in Universities of Shandong, Taishan Medical University, Taian, Shandong 271000, P.R. China
}

Received March 18, 2017; Accepted September 27, 2017

DOI: $10.3892 / \mathrm{mmr} .2017 .7730$

\begin{abstract}
Tumor angiogenesis provides essential nutrients and oxygen to the tumor microenvironment, which is important in tumor growth, progression and metastasis. Inhibition of tumor angiogenesis represents one of the most promising strategies in tumor therapy. The authors previously demonstrated that caudatin, one species of C-21 steroidal from Cynanchum auriculatum (C. auriculatum), effectively inhibits human glioma growth in vitro and in vivo through triggering cell cycle arrest and apoptosis. However, little information regarding the antiangiogenic properties of caudatin in human glioma is available. Based on the author's previous study, the antiangiogenic effect of caudatin against human glioma was explored, and the underlying mechanism was investigated. The results suggested that caudatin treatment significantly inhibited HUVEC human umbilical vein endothelial cell proliferation, blocked the HUVECs migration, invasion and capillary-like tube formation by disturbing the vascular endothelial growth factor (VEGF)-VEGFR2-protein kinase B (AKT)/focal adhesion kinase (FAK) signal axis. Notably, caudatin treatment abolished the glioma cell growth by suppression of the in vivo angiogenesis, which involved FAK and AKT dephosphorylation and inhibition of VEGF expression. The findings validated the antiangiogenic potential of caudatin in hunting human glioma.
\end{abstract}

Correspondence to: Dr Cundong Fan, Key Lab of Cerebral Microcirculation in Universities of Shandong, Taishan Medical University, 2 Yingsheng East Road Taian, Shandong 271000, P.R. China

E-mail: tcdfan66@163.com

Dr Gang Li, Department of Neurosurgery, Qilu Hospital of Shandong University, 107 Jinan Culture Road, Jinan, Shandong 250012, P.R. China

E-mail: doctorligang@126.com

${ }^{*}$ Contributed equally

Key words: glioma, caudatin, migration, invasion, angiogenesis

\section{Introduction}

Angiogenesis, the formation of new blood vessels initiated by endothelial cell proliferation and migration, is necessary for tumors to provide nutrients and remove metabolic wastes continuously (1). Tumors cannot grow beyond a certain size without concomitant vascular bed expansion. Therefore, angiogenesis is a key step in tumor growth, and anti-angiogenesis has become an attractive therapeutic strategy in cancer treatment (2-4). Angiogenesis is regulated by multiple growth factors and cytokines. Among these factors, vascular endothelial growth factor (VEGF), generated by most cancer cells and endothelial cells as well, is one of the most potent angiogenic factors involved in tumor growth (5). VEGF stimulates endothelial cell proliferation, migration and tube formation by binding its receptor tyrosine kinases expressed on endothelial cells. In these receptor tyrosine kinases, VEGF receptor 2 (VEGFR2) mediates the major function (6). Activation of VEGFR2 leads to activation of various downstream signal transduction proteins, including focal adhesion kinase (FAK), phosphoinositide 3-kinase $(\mathrm{PI} 3 \mathrm{~K}) /$ protein kinase B (AKT) (7). Inhibition of VEGF activity or/and disabling the function of VEGFR2 are both accepted as potential strategies for antiangiogenesis intervention in tumor treatment.

Natural products present promising application in cancer therapy due to their special pharmacological activities and low toxicity. Cynanchum auriculatum (C. auriculatum) is a traditional herb medicine mainly distributed in China and other Asian countries (8). C-21 steroidal glycoside, the major active component of $C$. auriculatum, showed multiple bioactivities, including anti-proliferation and invasion of tumor cells (9-12). Caudatin, isolated from the root of $C$. auriculatum, is a species of C-21 steroidal glycosides (13). The chemical structure of caudatin can be found in our previous publication (8). It is reported that caudatin could inhibit tumor growth via inducing cell cycle arrest in several cell lines $(10,13)$ or inducing apoptosis through various signal pathway in several cell lines such as human hepatoma cell line SMMC7721 $(10,14,15)$ and HepG2 cells $(10,16,17)$, human alveolar basal epithelial cell line A549 (18) and gastric cancer cells (19). In our previous studies, caudatin 
was demonstrated effective in inducing cell cycle arrest (8) and inducing apoptosis (13) in human glioma cells in vitro and in vivo. However, the anti-angiogenesis effect of caudatin on human glioma has not been explored yet, and the underlying mechanism remains elusive.

Herein, the antiangiogenesis properties and the underlying mechanism of caudatin on human glioma cells were investigated, and the results suggested that caudatin significantly inhibited endothelial cell proliferation and blocked the human umbilical vein endothelial cell (HUVEC) migration, invasion and capillary-like tube formation by disturbing the VEGF-VEGFR2-AKT/FAK signal axis, and eventually resulted in the inhibition of glioma growth in vivo.

\section{Materials and methods}

Materials. Caudatin was purchased from Sigma-Aldrich (St. Louis, MO, USA), and dissolved with dimethyl sulfoxide (DMSO). Cell culture reagents and fetal bovine serum (FBS) were procured from Invitrogen (Carlsbad, CA, USA). The second antibody IgG (cat. no. 3452) and all of the primary antibodies used in this study were both purchased from Cell Signaling Technology (Beverly, MA, USA), including p-FAK (cat. no. 3281), VEGF (cat. no. 2463), VEGFR2 (cat. no. 9698), p-VEGFR2 (cat. no. 2478S), AKT (cat. no. 9272), p-AKT (cat. no. 4060), Ki67 (cat. no. 9027) and CD34 (cat. no. 3569). LY294002 was obtained from Calbiochem (San Diego, CA, USA). PF-562271 was obtained from Selleck Chemicals (Houston, TX, USA). All solvents used were of high-performance liquid chromatography (HPLC) grade. Water used in this study was provided by a Milli-Q water purification system from Merck Millipore (Billerica, MA, USA).

Cell culture. HUVECs were purchased from the KeyGen Biotech (Nanjing, China) and cultured in DMEM-F12 medium supplemented with $10 \% \mathrm{FBS}, 100 \mathrm{U} / \mathrm{ml}$ penicillin and $50 \mathrm{U} / \mathrm{ml}$ streptomycin. Cells were maintained in a humidified incubator of $5 \% \mathrm{CO}_{2}$ at $37^{\circ} \mathrm{C}$.

Measurement of cell viability. Cell viability was measured with 3-(4,5-dimethylthiazol-2-yl)-2, 5-diphenyltetrazoliumbromide (MTT) assay. Briefly, HUVECs were cultured in a 96-well plate $\left(6 \times 10^{3}\right.$ cells/well) for $24 \mathrm{~h}$ and then were treated with indicated concentrations of caudatin for $48 \mathrm{~h}$. After that, $20 \mu \mathrm{l}$ MTT $(5 \mathrm{mg} / \mathrm{ml})$ solution/well was added and maintained for $4 \mathrm{~h}$. Then, the supernatant was removed, and $200 \mu \mathrm{l}$ DMSO/well was added, followed by 20 min shake to dissolve the formazan crystals. Subsequently, the absorbance at $570 \mathrm{~nm}$ was measured with a microplate reader (Molecular Device, USA). Cell viability was expressed as percentage of control (as $100 \%)$. Cell morphology was observed by inverted microscope (magnification, x200).

Migration assay. Wound healing assay was used to evaluate cell migration. HUVECs seeded in 6-well culture plate were incubated to full monolayer. Monolayer HUVECs were wounded by scratching with a pipette tip and washed twice with phosphate buffer solution (PBS). Fresh medium containing $1 \%$ FBS was then added together with caudatin or other reagents as designed. Cells were photographed under a Nikon Ti-S inverted microscope at the beginning and after incubation for $48 \mathrm{~h}$ (magnification, x100; Nikon Corporation, Tokyo, Japan). Cell migration distance was measured by image plus software, and the migrated rate was expressed as percentage of control. Three independent experiments were performed.

Invasion assay. Transwell assay was used to determine the effect of caudatin on HUVECs invasion. Transwell chambers (BD Biosciences, Bedford, MA, USA) containing a 6.5 -mm-diameter polycarbonate filter with a pore size of $8 \mu \mathrm{m}$ were used. Briefly, each filter was coated with $60 \mu \mathrm{l}$ Matrigel (1 mg/ml; BD Biosciences) diluted with DMEM-F12 and incubated at $37^{\circ} \mathrm{C}$ for $45 \mathrm{~min}$. HUVECs ( $4 \times 10^{4}$ cells) suspended in $100 \mu 1$ DMEM-F12 (FBS-free) were seeded in the filter, and treated with or without $100 \mu \mathrm{M}$ caudatin for $24 \mathrm{~h}$. Complete DMEM-F12 (600 $\mu \mathrm{l}, 10 \%$ FBS) was added into the chamber below. VEGF $(200 \mathrm{ng} / \mathrm{ml})$ and cisplatin $(5 \mu \mathrm{M})$ were employed as the positive and negative control, respectively. After incubation, the cells on the filter were wiped away, and the invaded cells below the filter were washed with PBS, fixed with $90 \%$ ethanol and stained with $0.1 \%$ crystal violet. The invaded cells were calculated by manual counting with a Nikon Ti-S inverted microscope (magnification, x200). The invaded rate was expressed as percentage of the control. Three independent experiments were performed.

Tube formation. Capillary-like tube formation assay was used to further detect the antiangiogenesis effect of caudatin. Matrigel was pipetted into 48 -well plate $(60 \mu \mathrm{l} /$ well $)$ and polymerized at $37^{\circ} \mathrm{C}$ for $45 \mathrm{~min}$. HUVECs $\left(100 \mu \mathrm{l}, 1 \times 10^{4}\right.$ cells/well $)$ mixed with $100 \mu \mathrm{M}$ caudatin were seeded into Matrigel pre-coated wells and incubated at $37^{\circ} \mathrm{C}$ with $5 \% \mathrm{CO}_{2}$ for $24 \mathrm{~h}$. Cells were photographed and the tube number was calculated by manual counting using a Nikon Ti-S inverted microscope (magnification, x100). Tube formation was scored as follows: A three branch point event was defined as one tubular structure. Eight random fields per well were quantified by manual counting. Three independent experiments were performed.

Western blotting. Western blot analysis was performed as described before (8). HUVECs were cultured in dishes $(10 \mathrm{~cm})$ and treated with indicated concentrations of caudatin or other reagents for $48 \mathrm{~h}$. Then, cells were washed twice by PBS and lysed in RIPA lysis buffer (1xPBS, 1\% NP40, 0.1\% SDS, $5 \mathrm{mM}$ EDTA, $0.5 \%$ sodium deoxycholate and $1 \mathrm{mM}$ sodium orthovanadate) for $20 \mathrm{~min}$ in the ice environment. Lysates were centrifuged and supernatants were kept as total cell protein. The concentration of total cell protein was quantified by bicinchoninic acid assay (BCA; Beyontime, Beijing, China) according to the manufacturer's instructions. Total protein was added with sample loading buffer, boiled for $10 \mathrm{~min}$ to be denatured, and stored at $-80^{\circ} \mathrm{C}$ environment for subsequent SDS-polyacrylamide gel electrophoresis (SDS-PAGE) analysis. Briefly, total protein (40 $\mu \mathrm{g} /$ lane) was separated by SDS-PAGE and then transferred onto polyvinylidene difluoride (PVDF) membranes (Merck Millipore). After that, the membranes were blocked with $5 \%$ bovine serum albumin (BSA) at room temperature for $2 \mathrm{~h}$. Then, the membranes were incubated with specific primary antibodies overnight at $4^{\circ} \mathrm{C}$ 
A

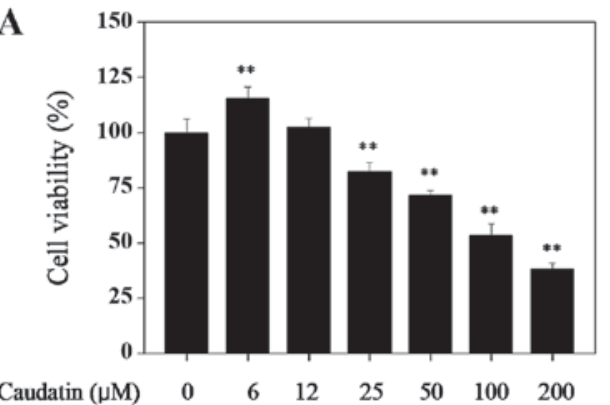

B

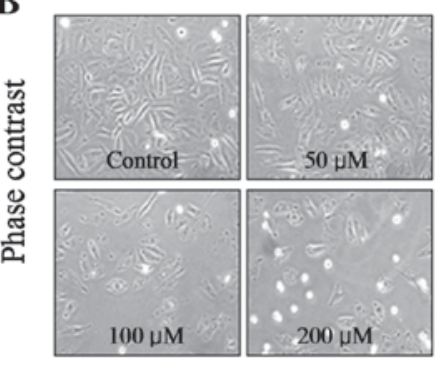

Figure 1. Caudatin inhibits cell proliferation of HUVECs. (A) Cytotoxicity of caudatin towards HUVECs. Cells were treated with caudatin (0-200 $\mu$ M) for $48 \mathrm{~h}$, and cell viability was detected by MTT assay. (B) Morphological changes. Cell morphology was observed by phase contrast microscope (magnification, $\mathrm{x} 200$ ). All data were expressed as the mean \pm SD of the three independent experiments. Bars with ${ }^{* *}$ indicate the statistical difference at P<0.01 when compared to the control group.

and secondary antibodies for $2 \mathrm{~h}$ at room temperature sequentially. At last, target protein bands were visualized with ECL under an Imaging System (ChemiDoc MP, Bio-Rad). $\beta$-actin plays as a positive control.

In vivo antiangiogenesis. U251 human glioma cells xenograft model was constructed as described previously (13). Briefly, $1 \times 10^{7} \mathrm{U} 251$ cells in $100 \mu \mathrm{l}$ serum-free medium were subcutaneously injected into the right oxter of male nude mice. When tumors grew to $60 \mathrm{~mm}^{3}$ on average after 8 days, mice were randomly divided into control group and the caudatin-treated groups (25 and $100 \mathrm{mg} / \mathrm{kg}$ ). Drugs were given through caudal vein injection every other day for 16 days. At the termination of the experiment, tumors were collected and used for western blotting and immunohistochemical (IHC) assay (magnification, x200). All animal experiments were approved by the Animal Experimentation Ethics Committee.

\section{Results}

Caudatin inhibits cell proliferation of HUVECs. Firstly, MTT assay was employed to examine the anti-proliferation activity of caudatin against HUVECs. As shown in Fig. 1, treatment of HUVECs with caudatin (below $12 \mu \mathrm{M}$ ) showed no cytotoxicity. Treatment of cells with $6 \mu \mathrm{M}$ caudatin slightly promoted $\mathrm{U} 251$ cells growth. However, caudatin (25-200 $\mu \mathrm{M})$ significantly inhibited U251 cells growth in a dose-dependent manner. For instance, cells exposed to 50,100 and $200 \mu \mathrm{M}$ of caudatin for $48 \mathrm{~h}$ markedly inhibited the HUVECs viability to 71.5, 53.6 and $38.1 \%$, respectively. This result suggests that caudatin may act as a potential cytostatic agent in hunting HUVECs growth.

Caudatin blocks HUVECs migration, invasion and capillary-like tube formation. Wound-healing assay, Transwell assay and capillary-like tube formation were used to evaluate the inhibition effect of caudatin on cell migration, invasion and tube formation, respectively. VEGF and cisplatin were employed as positive and negative control respectively in these assays to evaluate caudatin's potential. Cell migration and invasion is critical for endothelial cells to form blood vessels during angiogenesis. As shown in Fig. 2, VEGF obviously promoted cell migration (Fig. 2A and B), invasion (Fig. 2C and D) and capillary-like tube formation (Fig. 2E and F). However, caudatin $(100 \mu \mathrm{M})$ treatment effectively blocked HUVECs migration, invasion and capillary-like tube formation (Fig. 2). The statistical data of migrated rate, invaded rate and the tube formation further confirmed caudatin's inhibitory effects, which is similar with that of cisplatin. These results showed that caudatin has the potential to block the capillary-like tube formation in vitro by inhibiting the HUVECs migration and invasion.

Caudatin suppresses FAK phosphorylation in HUVECs. FAK is an upstream kinase that has a key role in the regulation of cell migration and invasion. Therefore, it was interested to investigate whether FAK was involved in the caudatin-induced inhibition of HUVEC migration and invasion. A specific antibody against the phosphorylated (activated) form of FAK was used (Fig. 3). The results showed that caudatin treatment caused significant dephosphorylation of FAK in a dose- and time-dependent manner (Fig. 3A and B). To further confirm the role of FAK, wound healing assay was operated using the specific FAK inhibitor (PF562271). As shown in Fig. 3D and E, pretreatment of HUVECs with PF562271 (10 nM) for $1 \mathrm{~h}$ markedly enhanced caudatin-induced inhibition against cell migration, which confirmed the effect of inactivation FAK on cell migration inhibition. Results in protein levels further confirmed this conclusion. Treatment of HUVECs with caudatin caused significant inactivation of FAK, and this effect was enhanced at the presence of PF562271 (Fig. 3C). Taken together, the results above suggest that caudatin can inhibit cell migration of HUVECs through FAK dephosphorylation.

Caudatin disturbs the VEGF-VEGFR2-AKT signal axis. The VEGF-VEGFR2- AKT signal axis has key roles in regulation of cell proliferation, cell growth, survival and angiogenesis. Therefore, it was of interest to investigate whether the VEGF-VEGFR2-AKT signal axis was involved in the caudatin-induced inhibition against HUVECs proliferation and angiogenesis. Firstly, western blotting assay was employed and different concentrations of caudatin on the VEGF-VEGFR2-AKT signal axis expression was assayed, and the results showed that caudatin treatment significantly suppressed the expression of VEGF and p-VEGFR2 in a dose-dependent manner (Fig. 4A), but caused no significant changes in the expression of total-VEGFR2 and total-AKT. To further confirm the role of the VEGF-VEGFR2- AKT signal axis, cell viability was detected by MTT assay using a specific AKT inhibitor (LY294002). As shown in Fig. 4B, pre-treatment 

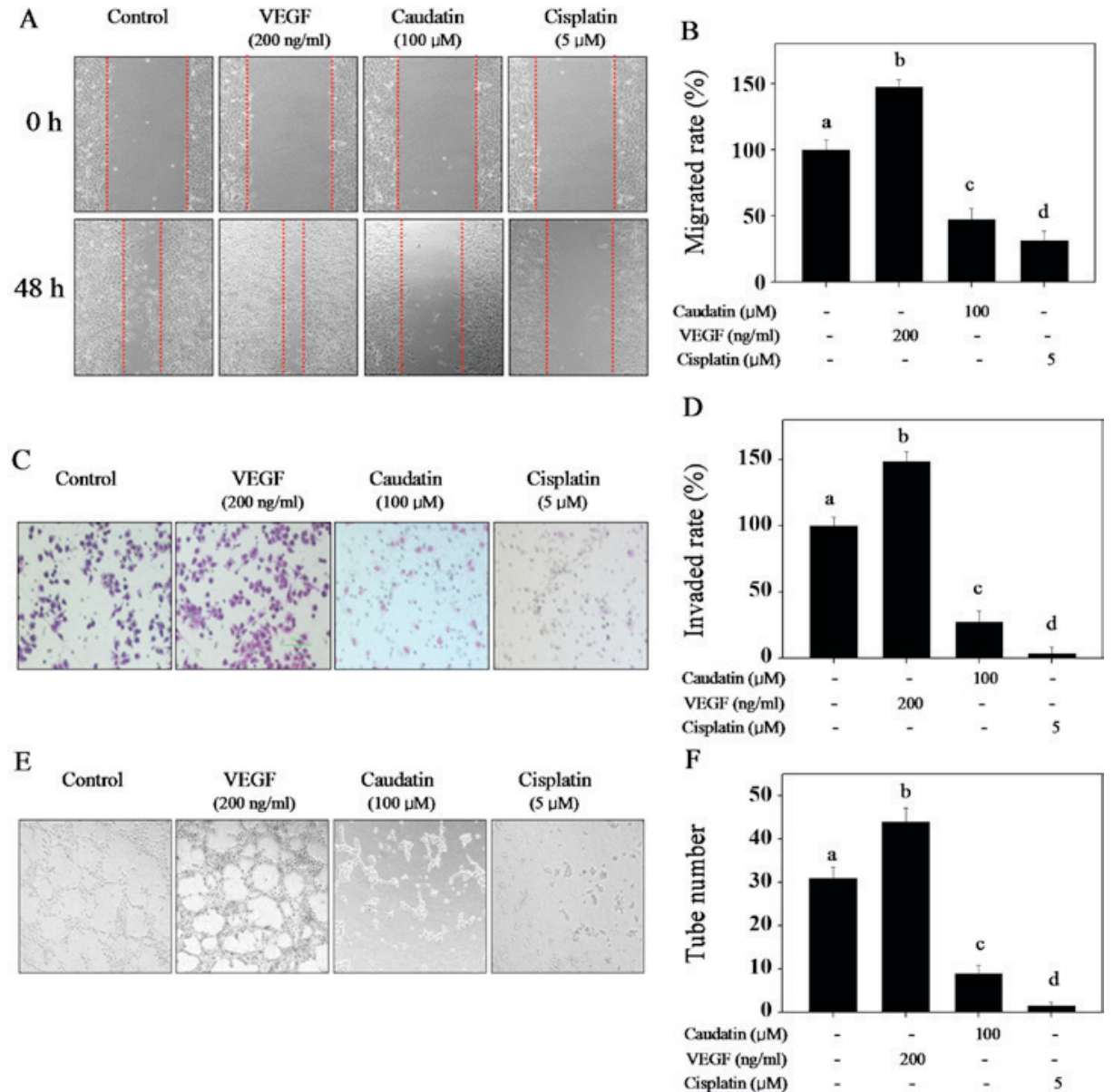

Figure 2. Caudatin blocks HUVEC cell migration, invasion and capillary-like tube formation. HUVEC cell migration (A and B), invasion (C and D) and tube formation (E and F) were detected by wound-healing assay, Transwell and Matrigel assay, respectively. VEGF and cisplatin were employed as the positive and negative control, respectively. Different letters on bars are statistically different at $\mathrm{P}<0.05$ level when compared between any two groups. HUVEC, human umbilical vein endothelial cells; VEGF, vascular endothelial growth factor.

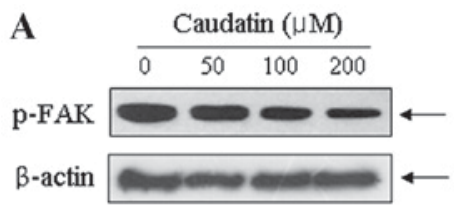

B
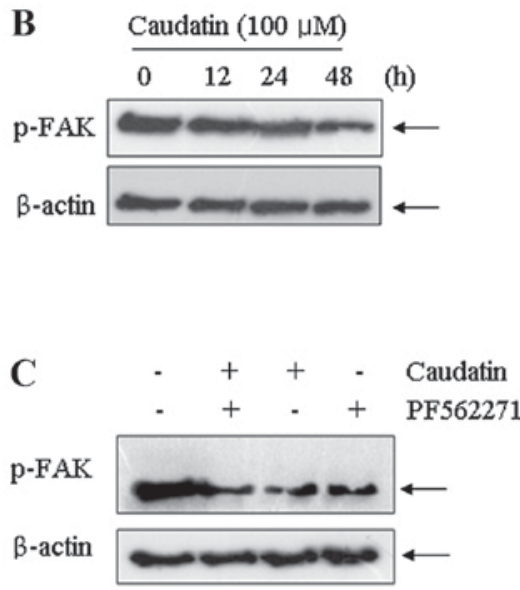
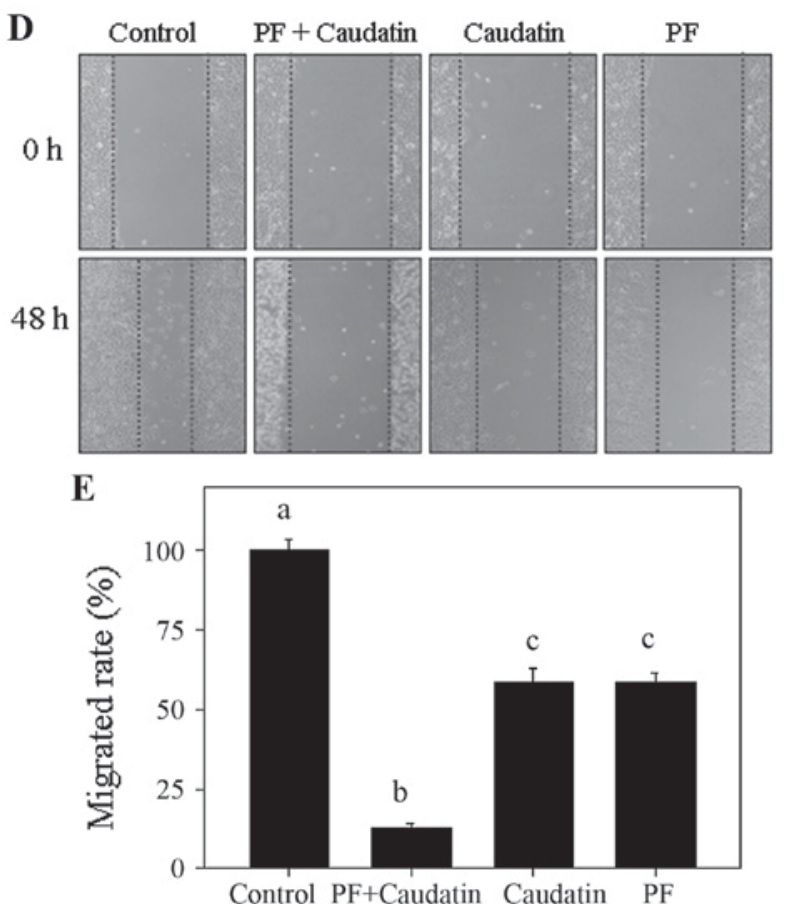

Figure 3. Caudatin suppresses FAK-dependent cell migration of HUVECs. Dose-dependent (A) and time-dependent (B) effects of caudatin on p-FAK expression. (C) FAK inhibitor (PF562271) enhanced caudatin-induced FAK inactivation. Protein expression was detected by western blotting. (D and E) FAK inhibitor enhances caudatin-induced migration inhibition against HUVECs. Cells were pre-treated with $10 \mathrm{nM}$ PF562271 for $1 \mathrm{~h}$ before caudatin treatment. Different letters on bars are statistically different at $\mathrm{P}<0.05$ level when compared between any two groups. HUVEC, human umbilical vein endothelial cells; FAK, focal adhesion kinase. 
A

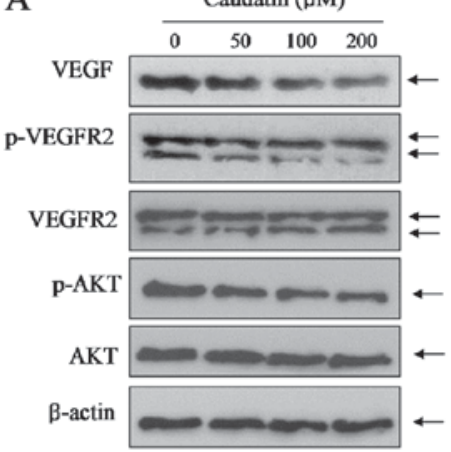

B

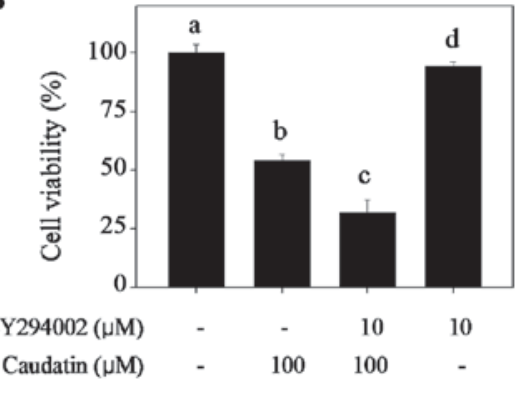

Figure 4. Caudatin disturbs the VEGF-VEGFR2-AKT signal axis. (A) Caudatin suppressed the expression of VEGF-VEGFR2-AKT signal axis. (B) AKT inhibitor (LY294002) enhanced caudatin-induced growth inhibition against HUVECs. Cells were pre-treated with $10 \mu \mathrm{M}$ LY294002 for 2 h before caudatin treatment. Cell viability was determined by MTT assay. Different letters on bars are statistically different at P<0.05 level when compared between any two groups. HUVEC, human umbilical vein endothelial cells; VEGF, vascular endothelial growth factor; AKT, protein kinase B; MTT, 3-(4,5-dimethylthiazol-2-yl)-2, 5-diphenyltetrazoliumbromide.

A

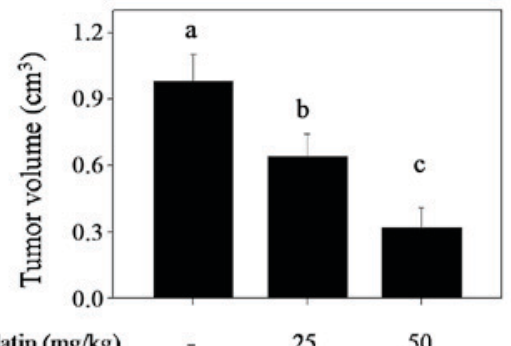

Caudatin $(\mathrm{mg} / \mathrm{kg})$

C

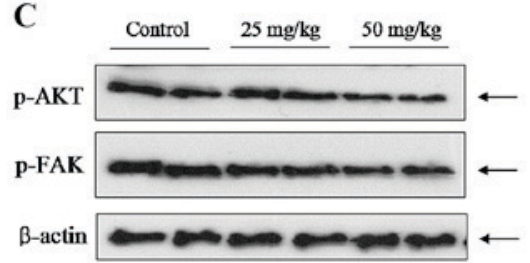

B

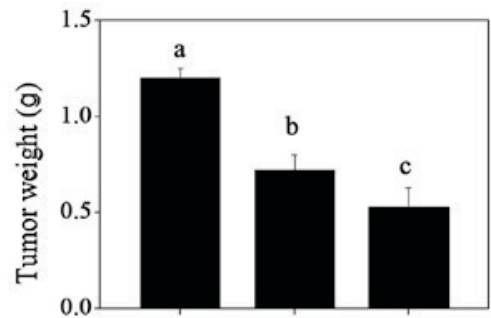

25

50

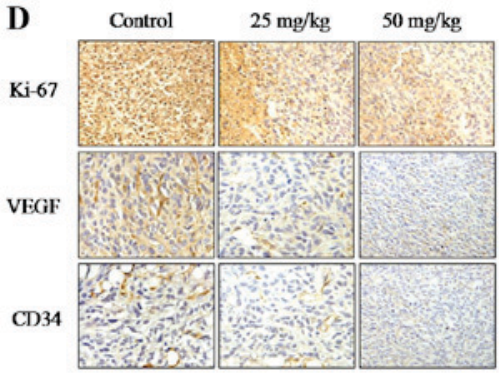

Figure 5. Caudatin hinders in vivo angiogenesis. Caudatin inhibited the tumor volume (A) and tumor weight (B). (C) Caudatin suppressed the expressions of phosphorylated AKT and FAK in tumor xenograft. (D) Effects of caudatin on Ki-67, VEGF and CD-34 expression in vivo. Different letters on bars are statistically different at $\mathrm{P}<0.05$ level when compared between any two groups. AKT, protein kinase; FAK, focal adhesion kinase; VEGF, vascular endothelial growth factor.

of HUVECs with LY294002 (an AKT-upstream inhibitor) for $1 \mathrm{~h}$ markedly enhanced caudatin-induced cell growth inhibition against HUVECs, indicating that caudatin inhibited HUVEC proliferation with AKT-dependent manner. These results indicated that the disturbance of VEGF-VEGFR2-AKT signal axis contributed to caudatin-induced inhibition against proliferation and angiogenesis.

Caudatin hinders the glioma growth by inhibiting in vivo angiogenesis. To investigate the antiangiogenesis effect of caudatin in vivo, immune-deficient nude mice bearing U251 xenograft tumors were employed (Fig. 5). The results demonstrated that caudatin treatment in vivo significantly inhibited U251 cell xenograft tumor growth, as convinced by the decrease of tumour volume (Fig. 5A) and tumor weight (Fig. 5B) and ki-67 expression (Fig. 5D). Moreover, CD-34, one of the endothelial cell markers, was detected in xenograft tumors by IHC method, and the results clearly demonstrated that caudatin treatment obviously abolished the tumor angiogenesis in vivo. VEGF expression as one of the most important pro-angiogenic factors also showed dramatically decrease (Fig. 5D). Furthermore, caudatin treatment caused the dephosphorylation of AKT and FAK detected by western blotting, which further affirmed the inhibitory effect of caudatin on glioma angiogenesis. Taken together, these results above suggest that caudatin can inhibit glioma cells growth by suppression of the in vivo angiogenesis involving the FAK and AKT dephosphorylation and inhibition of VEGF expression.

\section{Discussion}

Recently, great efforts have been made to identify anticancer agents which can block insurgence of primary tumors or recurrence. Current interest is focusing on the beneficial 
effects of phytochemicals (20), which have been found to influence some steps in cancer angiogenesis besides their traditional application (21). Angiogenesis is essential to the growth of solid tumors and inhibition of angiogenesis is an effective and promising target for anticancer therapy. Caudatin is a bioactive C-21 steroidal glycoside extracted from the root of $C$. auriculatum. Our previous studies have revealed that caudatin had the potential to inhibit human glioma cells growth in vitro and in vivo through triggering cell cycle arrest or/and apoptosis $(8,13)$. However, little information about the antiangiogenic effect of caudatin was available. Therefore, in the present study, we evaluated the antiangiogenic effect and mechanism of caudatin in human glioma in vitro and in vivo.

Rapid proliferation of cancer cells usually causes the intracellular hypoxia environment, which in turn accelerates the development of new blood vessels (22). VEGF as the most important pro-angiogenic factors was involved in almost every stage of tumor angiogenesis (23-25). Increasing studies have indicated that VEGF was capable of stimulating endothelial cell proliferation, migration and formation of new capillaries from pre-existing vasculature, which are all key steps in the process of angiogenesis $(26,27)$. VEGF can supply pro-survival and pro-angiogenic signals to normal and tumor-derived endothelial cells, which is mainly mediated by VEGF receptors, including VEGFR1, VEGFR2 and VEGFR3 (28). VEGFR2, a receptor tyrosine kinase, can be activated by autophosphorylation through binging of VEGF, which subsequently activated the secondary messengers including AKT, ERK and FAK to regulate endothelial cell proliferation, migration and angiogenesis (29-34). In the present study, exposure of HUVECs to caudatin resulted in the suppression of VEGF and p-VEGFR2 expression. The results indicated that caudatin can act as the inhibitor of VEGF and VEGFR2 to inhibit HUVECs migration, invasion and angiogenesis.

It is reported that overexpression of FAK in endothelial cells can promote the endothelial cell migration, invasion and angiogenesis $(31,35)$. Inactivation of FAK by conditional knockout mice could disrupt angiogenesis in late-stage embryos (36). Therefore, FAK inhibition may result in an antiangiogenic effect and was considered as novel anticancer strategy (32). Our data showed that caudatin treatment timeand dose-dependent suppressed FAK phosphorylation. FAK inhibitor (PF562271) effectively enhanced caudatin-induced inhibition against HUVECs migration. The results in vivo also that caudatin inhibited the glioma growth involving the suppression of FAK phosphorylation. These results all validated the contribution of FAK dephosphorylation to caudatin-induced inhibition against HUVECs migration.

VEGF and VEGFR2 regulate endothelial cell survival and proliferation through activating the PI3K/AKT signal (37). AKT is recruited during signal transduction from growth factor receptors and intracellular pathways (37). AKT activation not only promotes endothelial cell survival but also regulates vasomotor responses $(37,38)$. Overexpression of PI3K/AKT has been shown to induce angiogenesis and regulate tumor growth (39-41). In the present study, caudatin treatment causes obvious inhibition of AKT both in vitro and in vivo. PI3K inhibitor further confirmed the AKT-dependent effect of caudatin-induced cell killing.

\section{In conclusion}

In the present study, the antiangiogenic properties and mechanism of caudatin in vitro and in vivo was investigated, and the results suggested that caudatin had the potential to inhibit HUVECs proliferation, migration, invasion and capillary-like tube formation in vitro and in vivo through suppression of the VEGF-VEGFR2-AKT/FAK signal axis. Our findings validated the antiangiogenic potential of caudatin in the tumor chemotherapy.

\section{Acknowledgments}

The present study was supported by the National Natural Science Foundation of China grant no. 81571284 to G. Li. Key Research and Development Program of Shandong no. 2016GSF202036 to CD. Fan.

\section{References}

1. Carmeliet $\mathrm{P}$ and Baes $\mathrm{M}$ : Metabolism and therapeutic angiogenesis. N Engl J Med 358: 2511-2512, 2008.

2. Berz D and Wanebo H: Targeting the growth factors and angiogenesis pathways: Small molecules in solid tumors. J Surg Oncol 103: 574-586, 2011.

3. Burstein HJ and Schwartz RS: Molecular origins of cancer. N Engl J Med 358: 527, 2008.

4. Carmeliet P and Jain RK: Molecular mechanisms and clinical applications of angiogenesis. Nature 473: 298-307, 2011

5. Kerbel RS: Tumor angiogenesis. N Engl J Med 358: 2039-2049, 2008.

6. Ferrara $\mathrm{N}$ : Vascular endothelial growth factor: Basic science and clinical progress. Endocr Rev 25: 581-611, 2004.

7. Pyun BJ, Choi S, Lee Y, Kim TW, Min JK, Kim Y, Kim BD, Kim JH, Kim TY, Kim YM and Kwon YG: Capsiate, a nonpungent capsaicin-like compound, inhibits angiogenesis and vascular permeability via a direct inhibition of Src kinase activity. Cancer Res 68: 227-235, 2008.

8. Fu XY, Zhang S, Wang K, Yang MF, Fan CD and Sun BL: Caudatin inhibits human glioma cells growth through triggering DNA damage-mediated cell cycle arrest. Cell Mol Neurobiol 35: 953-959, 2015.

9. Li X, Zhang M, Xiang C, Qin Y, He J, Li BC and Li P: C21 steroids from roots of Cynanchum otophyllum. Zhongguo Zhong Yao Za Zhi 39: 1450-1456, 2014 (In Chinese).

10. Peng Y and Ding Y: Pharmacokinetics and tissue distribution study of caudatin in normal and diethylnitrosamine-induced hepatocellular carcinoma model rats. Molecules 20: 4225-4237, 2015.

11. Wang YQ, Yang B, Zhang RS and Wei EQ: Inhibitive effect of C-21 steroidal glycosides of Cynanchum auriculatum on rat glioma cells in vitro. Zhejiang Da Xue Xue Bao Yi Xue Ban 40: 402-407, 2011 (In Chinese)

12. Wang YQ, Zhang SJ, Lu H, Yang B, Ye LF and Zhang RS: A C 21 -steroidal glycoside isolated from the roots of cynanchum auriculatum induces cell cycle arrest and apoptosis in human gastric cancer SGC-7901 cells. Evid Based Complement Alternat Med 2013: 180839, 2013.

13. Zhu LZ, Hou YJ, Zhao M, Yang MF, Fu XT, Sun JY, Fu XY, Shao LR, Zhang HF, Fan CD, et al: Caudatin induces caspase-dependent apoptosis in human glioma cells with involvement of mitochondrial dysfunction and reactive oxygen species generation. Cell Biol Toxicol 32: 333-345, 2016.

14. Luo Y, Sun Z, Li Y, Liu L, Cai X and Li Z: Caudatin inhibits human hepatoma cell growth and metastasis through modulation of the Wnt/ß-catenin pathway. Oncol Rep 30: 2923-2928, 2013.

15. Peng YR, Ding YF, Wei YJ, Shu B, Li YB and Liu XD: Caudatin2,6 -dideoxy-3-O-methy- $\beta$-D-cymaropyranoside 1 induced apoptosis through caspase 3-dependent pathway in human hepatoma cell line SMMC7721. Phytother Res 25: 631-637, 2011.

16. Fei HR, Chen HL, Xiao T, Chen G and Wang FZ: Caudatin induces cell cycle arrest and caspase-dependent apoptosis in HepG2 cell. Mol Biol Rep 39: 131-138, 2012. 
17. Wang LJ, Chen H, Ma YB, Huang XY, Geng CA, Zhang XM and Chen JJ: Design, synthesis and biological evaluation of caudatin analogs as potent hepatitis B virus inhibitors. Med Chem 11: $165-179,2015$

18. Fei HR, Cui LY, Zhang ZR, Zhao Y and Wang FZ: Caudatin inhibits carcinomic human alveolar basal epithelial cell growth and angiogenesis through modulating GSK3$\beta / \beta$-catenin pathway. J Cell Biochem 113: 3403-3410, 2012.

19. Li X, Zhang X, Liu X, Tan Z, Yang C, Ding X, Hu X, Zhou J, Xiang S, Zhou C and Zhang J: Caudatin induces cell apoptosis in gastric cancer cells through modulation of $\mathrm{Wnt} / \beta$-catenin signaling. Oncol Rep 30: 677-684, 2013.

20. Aggarwal BB and Shishodia S: Molecular targets of dietary agents for prevention and therapy of cancer. Biochem Pharmacol 71: 1397-1421, 2006

21. Ren W, Qiao Z, Wang H, Zhu L and Zhang L: Flavonoids: Promising anticancer agents. Med Res Rev 23: 519-534, 2003.

22. Carmeliet P, Dor Y, Herbert JM, Fukumura D, Brusselmans K, Dewerchin $\mathrm{M}$, Neeman $\mathrm{M}$, Bono $\mathrm{F}$, Abramovitch $\mathrm{R}$, Maxwell P, et al: Role of HIF-1alpha in hypoxia-mediated apoptosis, cell proliferation and tumour angiogenesis. Nature 394: 485-490, 1998

23. Bolat F, Haberal N, Tunali N, Aslan E, Bal N and Tuncer I: Expression of vascular endothelial growth factor (VEGF), hypoxia inducible factor 1 alpha (HIF-lalpha), and transforming growth factors beta1 (TGFbeta1) and beta3 (TGFbeta3) in gestational trophoblastic disease. Pathol Res Pract 206: 19-23, 2010.

24. Carmeliet P: Angiogenesis in life, disease and medicine. Nature 438: 932-936, 2005.

25. Ferrara $\mathrm{N}$ and Kerbel RS: Angiogenesis as a therapeutic target. Nature 438: 967-974, 2005

26. Holopainen T, Bry M, Alitalo K and Saaristo A: Perspectives on lymphangiogenesis and angiogenesis in cancer. J Surg Oncol 103 : 484-488, 2011.

27. Nussenbaum $F$ and Herman IM: Tumor angiogenesis: Insights and innovations. J Oncol 2010: 132641, 2010.

28. Ferrara N: VEGF and the quest for tumour angiogenesis factors Nat Rev Cancer 2: 795-803, 2002.

29. Le Boeuf F, Houle F and Huot J: Regulation of vascular endothelial growth factor receptor 2-mediated phosphorylation of focal adhesion kinase by heat shock protein 90 and Src kinase activities. J Biol Chem 279: 39175-39185, 2004.

30. Jośko J and Mazurek M: Transcription factors having impact on vascular endothelial growth factor (VEGF) gene expression in angiogenesis. Med Sci Monit 10: RA89-RA98, 2004.
31. Parsons JT: Focal adhesion kinase: The first ten years. J Cell Sci 116: 1409-1416, 2013.

32. Braren R, Hu H, Kim YH, Beggs HE, Reichardt LF and Wang R: Endothelial FAK is essential for vascular network stability, cell survival, and lamellipodial formation. J Cell Biol 172: 151-162, 2006.

33. Holmqvist K, Cross MJ, Rolny C, Hägerkvist R, Rahimi N, Matsumoto T, Claesson-Welsh L and Welsh M: The adaptor protein shb binds to tyrosine 1175 in vascular endothelial growth factor (VEGF) receptor-2 and regulates VEGF-dependent cellular migration. J Biol Chem 279: 22267-22275, 2004.

34. Qi JH and Claesson-Welsh L: VEGF-induced activation of phosphoinositide 3-kinase is dependent on focal adhesion kinase. Exp Cell Res 263: 173-182, 2001.

35. Mitra SK, Mikolon D, Molina JE, Hsia DA, Hanson DA, Chi A, Lim ST, Bernard-Trifilo JA, Ilic D, Stupack DG, et al: Intrinsic FAK activity and Y925 phosphorylation facilitate an angiogenic switch in tumors. Oncogene 25: 5969-5984, 2006.

36. Shen TL, Park AY, Alcaraz A, Peng X, Jang I, Koni P, Flavell RA, $\mathrm{Gu} \mathrm{H}$ and Guan JL: Conditional knockout of focal adhesion kinase in endothelial cells reveals its role in angiogenesis and vascular development in late embryogenesis. J Cell Biol 169: 941-952, 2005

37. Shiojima I and Walsh K: Role of Akt signaling in vascular homeostasis and angiogenesis. Circ Res 90: 1243-1250, 2002.

38. Fresno Vara JA, Casado E, de Castro J, Cejas P, Belda-Iniesta C and González-Barón M: PI3K/Akt signalling pathway and cancer. Cancer Treat Rev 30: 193-204, 2004.

39. Jiang BH, Zheng JZ, Aoki M and Vogt PK: Phosphatidylinositol 3-kinase signaling mediates angiogenesis and expression of vascular endothelial growth factor in endothelial cells. Proc Natl Acad Sci USA 97: 1749-1753, 2000.

40. Fan C, Zheng W, Fu X, Li X, Wong YS and Chen T: Enhancement of auranofin-induced lung cancer cell apoptosis by selenocystine, a natural inhibitor of TrxR1 in vitro and in vivo. Cell Death Dis 5: e1191, 2014

41. Fan C, Zheng W, Fu X, Li X, Wong YS and Chen T: Strategy to enhance the therapeutic effect of doxorubicin in human hepatocellular carcinoma by selenocystine, a synergistic agent that regulates the ROS-mediated signaling. Oncotarget 5: 2853-2563, 2014. 